\title{
Proteomic Analysis of Auricularia auricula-judae Under Freezing Treatment Revealed Proteins and Pathways Associated With Melanin Reduction
}

OPEN ACCESS

Edited by:

Lin Lin,

Jiangsu University, China

Reviewed by:

Ekaterina Dadachova,

University of Saskatchewan, Canada

Jameel Rabee Al-Obaidi,

National Institutes of Biotechnology

Malaysia, Malaysia

Zaixiang Lou,

Jiangnan University, China

*Correspondence:

Xiufeng Yan

yanxiufeng@wzu.edu.cn

Qiuying Pang

qiuying@nefu.edu.cn

${ }^{\dagger}$ These authors have contributed equally to this work

Specialty section: This article was submitted to

Food Microbiology,

a section of the journa

Frontiers in Microbiology

Received: 25 September 2020 Accepted: 09 December 2020

Published: 15 January 2021

Citation:

Li J, Li Z, Zhao T, Yan X and Pang Q (2021) Proteomic Analysis

of Auricularia auricula-judae Under

Freezing Treatment Revealed Proteins and Pathways Associated With

Melanin Reduction.

Front. Microbiol. 11:610173. doi: 10.3389/fmicb.2020.610173

\author{
Jiawen $\mathrm{Li}^{1+}$, Ziwei $\mathrm{Li}^{1+}$, Tong Zhao', Xiufeng Yan ${ }^{2 *}$ and Qiuying Pang ${ }^{1 *}$ \\ ${ }^{1}$ Key Laboratory of Saline-alkali Vegetation Ecology Restoration, Ministry of Education, College of Life Sciences, Northeast \\ Forestry University, Harbin, China, ${ }^{2}$ College of Life and Environmental Science, Wenzhou University, Wenzhou, China
}

Auricularia auricula-judae is an edible nutrient-rich mushroom, which is a traditional medicinal resource in China. It is known that environment stimuli will affect the production of melanin by $A$. auricula-judae, but the mechanism of the effects of freezing treatment on melanin accumulation remains unknown. In the present study, the synthesis of melanin in A. auricula-judae was analyzed by physiological assays and a proteomics approach. Our findings showed that a longer freezing treatment causes a lighter color of $A$. auricula-judae fruiting bodies. The proteomic analysis showed that proteins involved in glycolysis/gluconeogenesis, tyrosine metabolism, ribosome, and arginine biosynthesis might contribute to the color differences in the A. auricula-judae after freezing treatment. This work will be expected to provide valuable information on the physiological and molecular mechanisms of freezing treatment on the color quality of $A$. auricula-judae.

Keywords: Auricularia auricula-judae, freezing treatment, proteomics, mycelium, fruiting bodies

\section{INTRODUCTION}

Auricularia auricula-judae is an edible nutrient-rich mushroom, which is an important food resource in Asia due to it being rich in proteins, microelements, vitamins, and carbohydrates as well as its low fat content (Luo et al., 2009). A. auricula-judae is also known for its medicinal properties, such as its antitumor, detoxification, anticoagulant, hypoglycemic, and cholesterol-lowering effects (Nguyen et al., 2012). Wild A. auricula-judae is geographically distributed in Asia, Europe, North America, and other places throughout temperate and subtropical regions (Akpaja et al., 2005). A. auricula-judae has been cultivated on a large scale in northern China, with a yield that ranked fourth in the world (Zhang et al., 2007). With the improvement of the nutritional and medicinal values of A. auricula-judae, its harvesting method has gradually evolved from wild collection to artificial cultivation.

Auricularia auricula-judae is widely cultivated in China, and northern China was the major cultivation area (Li et al., 2019). In 2012, its production in Heilongjiang was more than 3,000,000 tons, with an output value of more than 20 billion yuan (Liu and $\mathrm{Hu}, 2018$ ). A. auricula-judae is mainly cultivated by two different methods, wood cultivation and bagging cultivation (Lv, 2008). 
Compared with wood cultivation, bagging cultivation (Supplementary Figure 1) is more widely used because of the lower expenses, including wood resources and economic investment, as well as the avoidance of pesticides and viruses ( $\mathrm{Lv}$, 2008). The freezing pretreatment of the mycelium is a common method and key step of bagging cultivation in northern China, and when producing cultivation species of $A$. auricula-judae in the winter, the cultivation species full of mycelium are put outdoors for quick-freezing, followed by waiting for ear emergence in the spring. Freezing treatment can significantly improve the yield and quality of A. auricula-judae (Gao, 2012), but the fruit color has been greatly affected, which is the most important indicator to estimate the food quality of $A$. auriculajudae. The color of A. auricula-judae fruiting bodies turned to yellow after the mycelium was frozen. However, we are still far from understanding the physiological and molecular bases of this phenomenon.

Auricularia auricula-judae melanin belongs to the 3,4dihydroxyphenylalanine (DOPA) melanin, and it was initially determined to be pheomelanin by Sephadex G-100 column chromatography, which is a complex polyphenolic compound (Zou et al., 2013). DOPA-based melanin is a natural pigment widely found in living organisms, and the hair of humans (Homo sapiens), bones and feathers of Gallus, seed coat of Armeniaca sibirica, and black truffles (Tuber melanosporum) contain a large amount of DOPA-like melanin (Butler and Day, 1998; Yao et al., 2007). The products in the biosynthesis process of DOPA melanin are divided into eumelanin (brown or black) and pheomelanin (brown, red, or yellow) (Zou et al., 2013). The color of melanin to eumelanin or pheomelanin during synthesis depends on the tyrosinase activity and substrate concentration of cysteine (Simon et al., 2009). When cysteine is present in the cell, dopaquinone (DQ) will immediately bind to cysteine to form cysteamine DOPA, and when most of the cysteamine DOPA in the cell is consumed, DOPA will undergo its own cyclization reaction to form a cyclized DOPA, eventually synthesizing pheomelanin (Ito and Wakamatsu, 2003). Studies have shown that tyrosinase activity is significantly reduced and even inactivated, which will directly affect the production of melanin by A. auriculajudae under strong-light, high-temperature, or cold conditions (Geib et al., 2016).

Until now, the quality changes of $A$. auricula-judae caused by environmental factors have not been studied using a comprehensive approach, such as proteomics analysis. Thus, this study will detect the protein expression profile to explore the physiological mechanism of the effects of freezing treatment on the color quality of $A$. auricula-judae. We aim to study the differences in protein abundances due to freezing treatment in A. auricula-judae and identify the roles of the identified differentially expressed proteins in the melanin biosynthesis process. Our findings are expected to provide a valuable picture of the physiological and molecular mechanisms of freezing treatment on the color quality of A. auricula-judae and provide a resource for the identification of key proteins contributing to the improvement in the concentration of melanin in A. auricula-judae.

\section{MATERIALS AND METHODS}

\section{Sample Treatment and Collection}

Auricularia auricula-judae (HW15) fruiting bodies are single monolithic; rootless; moderate in size; shaped like a shell or a bowl with round, thick, and soft edges; gray on the back of the dry ear; black on the abdomen; and shiny, with a big color difference between the front and the back and with an inconspicuous ear vein, and they were obtained from the experimental forestry farm of the Heilongjiang Academy of Forestry (Dai et al., 2014). They are cultured on a substitute medium in mycelium bags containing $78 \%$ saw dust, $20 \%$ bran, and $2 \%$ gypsum powder. The relative water content of the substitute medium was $65 \%$. All mycelium bags were stored at $25^{\circ} \mathrm{C}$ in the mycelium growing season until the surface of the mycelium bags became white, which meant that the mycelium was mature. Then, they were stored at $4^{\circ} \mathrm{C}$, and some mycelium bags were transferred outdoors as freezing treatment (Supplementary Figure 2). All fruiting bodies were quickly frozen in liquid nitrogen, ground to a fine powder using a mortar and pestle, and stored at $-80^{\circ} \mathrm{C}$ before protein extraction.

\section{Color Measurement}

The International Commission on Illumination (CIE) color system was applied to study the color changes of fruiting bodies during different levels of the freezing treatment. The CIE recommended the CIE L*a*b* color system in 1976 as a standard to describe an objective color (Takeshi et al., 2016). The color of fruiting bodies was measured by Color Testers (CR10, Konica Minolta). The $\mathrm{L}^{*}$ value indicates lightness (0-100 represent dark color-light color). The $a^{*}$ coordinate indicates redness and greenness in the positive $\left(+a^{*}\right)$ and negative $\left(-a^{*}\right)$ directions, respectively. The $b^{*}$ coordinate indicates yellowness and greenness for the positive $\left(+b^{*}\right)$ and negative $\left(-b^{*}\right)$ directions, respectively. When $b^{*}$ is positive, it is only related to the yellow color. The larger the $b^{*}$ value is, the yellower the color (Zielinska and Michalska, 2016).

\section{Enzyme Activity Assay}

Mycelium and fruiting bodies were ground to a fine powder in liquid nitrogen, fully mixed in extraction buffer, and centrifuged at $4^{\circ} \mathrm{C}$ at $15,000 \times g$ for $20 \mathrm{~min}$. The supernatant was then extracted for enzyme activity detection. Tyrosinase, laccase, superoxide dismutase (SOD), and peroxidase (POD) activities were examined by an ultraviolet (UV) spectrophotometer (Wang et al., 2013; Zhang et al., 2013).

\section{Mineral Element Analysis}

Inductively coupled plasma-optical emission spectroscopy (ICPOES, Optima 8300, Perkin Elmer) was used to detect the mineral elements in the mycelia and fruiting bodies of A. auriculajudae. The standard sample was purchased from the National Center of Analysis and Testing for Nonferrous Metals and Electronic Materials (China). The solution for element detection was prepared by ash nitration method. Fine powder was obtained by grinding the mycelia and fruiting bodies after drying, carbide 
samples were thereafter transferred to a muffle furnace (SX-410, China), ash treated at $625^{\circ} \mathrm{C}$, and then dissolved with $2 \%$ $\mathrm{HNO}_{3}$. ICP-OES operating conditions were as follows: plasma gas flow rate of $14 \mathrm{~L} \cdot \mathrm{min}^{-1}$, auxiliary gas flow rate of $0.2 \mathrm{~L} \cdot \mathrm{min}^{-1}$, atomizer gas flow rate of $0.55 \mathrm{~L} \cdot \mathrm{min}^{-1}, \mathrm{RF}$ power of $1200 \mathrm{~W}$, and sample flow rate of $1.5 \mathrm{~mL} \cdot \mathrm{min}^{-1}$.

\section{Protein Extraction}

The total protein was extracted from $10 \mathrm{~g}$ of fruiting bodies and $500 \mathrm{mg}$ of mycelium, according to the phenol-based protocol referring to Li et al. (2018). The fine powder was homogenized in extraction buffer $(0.9 \mathrm{M}$ sucrose, $0.1 \mathrm{M}$ Tris- $\mathrm{HCl}, 10 \mathrm{mM}$ EDTA, 1\% PVPP, 0.4\% $\beta$-mercaptoethanol, and Tris-phenol) for $0.5-2 \mathrm{~h}$ until the mixture turned into liquid, followed by centrifugation at $20,000 \times g$ for $20 \mathrm{~min}$ at $4^{\circ} \mathrm{C}$ and the collection of the phenol phase. The phenol phase was precipitated with five volumes of cold $0.1 \mathrm{M}$ ammonium acetate in methanol for $20 \mathrm{~min}$ at $-20^{\circ} \mathrm{C}$, and then, the precipitate was collected by centrifugation at $20,000 \times g$ for $20 \mathrm{~min}$ at $4^{\circ} \mathrm{C}$. After washing with $0.1 \mathrm{M}$ ammonium cold acetate and $80 \%$ acetone successively, pure protein powder was obtained. The protein powder was dissolved in lysis buffer (7 $\mathrm{M}$ urea, $2 \mathrm{M}$ thiourea, 4\% 3-[(3-cholamidopropyl) dimethylammonio]propanesulfonate (CHAPS), $40 \mathrm{mM}$ dithiothreitol (DTT), 2\% pharmalyte, and 4\% protease inhibitor). The protein concentration was determined using the 2-D Quant Kit (GE Healthcare, Little Chalfont, United Kingdom) with BSA as the standard. Samples were frozen in liquid nitrogen and kept at $-80^{\circ} \mathrm{C}$ for further use.

\section{Two-Dimensional Gel Electrophoresis (2-DE) and Image Analysis}

Two-dimensional electrophoresis (2-DE) of protein samples was performed as described previously (Li et al., 2018). A protein sample of $1300 \mu \mathrm{g}$ was loaded by rehydration to immobilize DryStrip gels $(\mathrm{pH}=3-10$ linear, $24 \mathrm{~cm})$ (GE Healthcare, Waukesha, WI, United States) individually. After automated detection and matching, manual editing was carried out to correct the mismatched and unmatched spots. Spots were considered reproducible when they were well resolved in the three biological replicates. For each matched spot, a measurement was carried out for each biological replicate, and normalized volumes were computed using the total spot volume normalization procedure of the software. The normalized volume of each spot was assumed to represent its expression abundance. A criterion of $p<0.05$ and an abundance ratio of at least 1.5 were used to define significant differences when analyzing parallel spots between different groups with two-way ANOVA.

\section{Protein Identification by Mass Spectrometry}

Selected spots were excised from 2-DE gels, washed with sterile deionized water, and digested with trypsin as described previously (Chen et al., 2011). The obtained dry protein was redissolved in $0.1 \%$ trichloroacetic acid and identified by mass spectrometry. MS/MS spectra were acquired using an ABI 5800 MALDI-TOF/TOF Plus mass spectrometer (Applied Biosystems,
Foster City, CA, United States). Data were acquired in a positive MS reflector using a CalMix5 A standard to calibrate the instrument (ABI5800 Calibration Mixture). Primary and secondary mass spectrometry data were integrated, and the results were analyzed and identified using GPS 3.6 (Applied Biosystems) and Mascot 2.3 (Matrix Science). Identification of proteins was performed using the following search parameters: NCBI-Auricularia, NCBI-fungi database, trypsin as the digestion enzyme and allowable maximum leakage cutting locus of 1 , fixed modification of carbamidomethyl (C), partial modifications of acetyl (protein N-term), deamidated (NQ), dioxidation (W), and oxidation (M), the MS tolerance was $100 \mathrm{ppm}$, the MS/MS tolerance was $0.3 \mathrm{Da}$, and a protein score CI\% of more than $95 \%$ indicates successful identification.

\section{Functional Categorization of Proteins}

The Kyoto Encyclopedia of Genes and Genomes (KEGG) (last updated on 1 November 2020) (Kanehisa et al., 2008) is a database resource for understanding high-level functions and utilities of a biological system, such as the cell, the organism, and the ecosystem, from molecular-level information, especially large-scale molecular datasets generated by genome sequencing and other high-throughput experimental technologies ${ }^{1}$. We used KOBAS software to test the statistical enrichment of differentially expressed proteins in KEGG pathways.

\section{UV-Visible/Fourier Transform Infrared (FTIR) Spectra of A. auricula-judae Melanin Analysis}

The powder of freeze-dried melanin is mixed with $\mathrm{KBr}$ (mass ratio $1: 200)$ and pressed into tablets, and the infrared (IR) spectrum $\left(500-4000 \mathrm{~cm}^{-1}\right)$ is recorded by a Fourier transform infrared (FTIR) spectrometer (Zou et al., 2013).

\section{Electron Paramagnetic Resonance (EPR) Analysis of $A$. auricula-judae Melanin Analysis}

The melanin of $A$. auricula-judae was extracted with $\mathrm{NaOH}$ and HCL and purified by using strong acid hydrolysis and organic solvent (Li, 2011). The purified melanin of A. auricula-judae was identified by EPR.

\section{qRT-PCR Analysis}

To validate the protein data, nine genes were chosen for RTPCR analysis. The total RNA was isolated with TRIzol reagent (Invitrogen) according to the manufacturer's instructions and then treated with recombinant DNase I (RNase-free, TaKaRa, Tokyo, Japan). Ten micrograms of RNA was used to synthesize the cDNA with the PrimeScript RT Reagent Kit (TaKaRa, Tokyo, Japan), and the cDNAs were used for RT-PCR analysis with specific primers (Supplementary Table 1). Quantitative RTPCR was performed using the Applied Biosystems 7500 RealTime PCR System using Power SYBR Green chemistry (TaKaRa, Tokyo, Japan). $18 \mathrm{~S}$ was quantified as an internal control, and

${ }^{1}$ http://www.genome.jp/kegg/ 
the $2^{-\Delta \Delta \mathrm{Ct}}$ method was used to analyze differential expression (Livak and Schmittgen, 2001). The mean of three biological replicates, for which three technical replicates were averaged, was presented. Genes were considered to be differentially expressed if the fold change was $\geq 1.5$ or $\leq 0.67$, and the $p$-value was tested by ANOVA with the post hoc Tukey test $(p<0.05)$.

\section{Statistical Analysis}

All statistical calculations were performed by the SPSS 17.0 software package for Windows (SPSS Inc., Chicago, IL, United States). All claims of statistical significance $(p<0.05)$ were assessed by Student's $t$-test and two-way ANOVA $(p<0.05)$ with Tukey HSD post hoc test.

\section{RESULTS}

\section{Color Analysis}

Under the treatments of outdoor freezing and $-40^{\circ} \mathrm{C}$ freezing, the color of the fruiting bodies was lighter with longer processing times. The color of fruiting bodies is not significantly different under different times of $-20^{\circ} \mathrm{C}$ freezing treatment (Figure 1A). The CIE test showed a greater $\mathrm{L}^{*}$ value of the fruiting bodies under different times of outdoor and $-40^{\circ} \mathrm{C}$ freezing treatments. After the outdoor and $-40^{\circ} \mathrm{C}$ freezing treatments, the $\mathrm{b}^{*}$ value of the fruiting bodies was increased after 2 months of freezing treatment and had no change after 3 or 4 months of treatment compared to 2 months. Under $-20^{\circ} \mathrm{C}$ freezing treatment, the $\mathrm{L}^{*}$ and $\mathrm{b}^{*}$ values of fruiting bodies did not continuously increase with the change of treatment time. The $a^{*}$ value of the fruiting bodies showed no significant alteration under three freezing treatments (Figure 1B). Combining the color observation and CIE test, we found that the color of fruiting bodies was significantly changed under 2 months of outdoor freezing treatment, which was quite brown compared to the control group, and the A. auricula-judae with outdoor freezing treatment for 2 months was used for the follow-up analysis. According to the phenotypic observation of A. auricula-judae, the biomass of the A. auricula-judae significantly increased under freezing treatment, which is consistent with previous research (Gao, 2012).

\section{Enzyme Activity Analysis}

During the freezing treatment, the changes in ambient temperature may cause oxidative stress, which affects the synthesis of DOPA melanin (Jarrar et al., 2017). To test if the color change of $A$. auricula-judae upon freezing treatment correlated with oxidative stress, we detected the activities of POD and SOD, the main antioxidative enzymes that would be induced by oxidative stress. The activities of POD and SOD in the mycelium were significantly increased after outdoor freezing treatment. In contrast, there is no significant difference comparing the control and treated groups in the fruiting bodies (Figures 2A,B). This indicated that the freezing treatment caused oxidative stress to the mycelium, which may affect the synthesis of melanin in the mycelium.
Tyrosinase and laccase are known to play a key role in melanin synthesis (Sapmak et al., 2015). We therefore analyzed whether freezing treatment could impact the tyrosinase and laccase enzyme activities. The activity of tyrosinase was inhibited, and laccase activity was enhanced in the mycelium after freezing treatment (Figures 2C,D), which indicates that freezing treatment inhibits the melanin synthetic process. The activities of tyrosinase and laccase in the fruiting bodies were significantly higher than those in the control group and far lower than those in the mycelium; therefore, we infer that the melanin synthesis begins in the mycelium stage. L-DOPA was synthesized from tyrosine, which was catalyzed by tyrosinase and then further became DQ in the mycelium stage. DQ may react with cysteamine or glutathione at the fruiting bodies stage for further oxidative polymerization to produce pheomelanin.

\section{Mineral Element Analysis}

Pheomelanin is a sulfur-containing macromolecule, a melanin synthesized by tyrosine, dopamine, dopamine, tyramine, cysteine, and glutathione (Prota, 1980). Some metal ions can activate or inhibit protease activities, such as high concentrations of $\mathrm{Cu}$ and $\mathrm{Zn}$ that can inhibit the activity of tyrosinase and laccase (Chen and Song, 2006). Thus, we detected S, Cu, and $\mathrm{Zn}$ elements by ICP-OES analysis. As shown in Figure 3, it was found that the contents of $\mathrm{S}$ and $\mathrm{Cu}$ elements in the mycelium were increased, but $\mathrm{Zn}$ was decreased after freezing treatment. Different situations happened in the fruiting bodies; the accumulation of $\mathrm{S}, \mathrm{Cu}$, and $\mathrm{Zn}$ was all significantly induced by freezing treatment (Figure 3), suggesting that the inhibition of melanin synthesis caused by freezing condition may be correlated with these elements.

\section{Protein Identification}

To analyze the underlying molecular network contributing to the regulation of the color change of $A$. auricula-judae under freezing treatment, a comparative proteomics analysis was performed, and the protein expression profile in A. auricula-judae was uncovered. We identified more than 1500 protein spots in the $\mathrm{CBB}$ staining $2 \mathrm{D}$ gels by the detection of ImageMaster 2D Platinum software. The isoelectric point of the protein is in the $\mathrm{pH}$ range of 3-10, and the molecular weight is between 14.4 and $1116.0 \mathrm{kDa}$ (Figure 4). Based on the fold change of more than 1.5 with a $p$-value $<0.05$ of variation in protein abundance, we detected a total of 51 and 36 differentially expressed protein spots in the mycelium and fruiting bodies after freezing treatment (Tables 1, 2). As shown, all proteins identified were supported by the MS/MS sequenced peptides. A total of 73 proteins were successfully identified according to peptide matching results using MASCOT (Supplementary Table 2). Among the 73 differentially expressed proteins, 12 proteins were upregulated and 27 proteins downregulated in the mycelium, while eight proteins were upregulated and 19 proteins downregulated in the fruiting bodies (Figure 5A); meanwhile, seven proteins in the mycelium and fruiting bodies failed to be identified. Among these distinct proteins, it was found that the expression of tyrosinase and laccase in the mycelium and fruiting bodies had no change after freezing treatment. This means that the regulation 


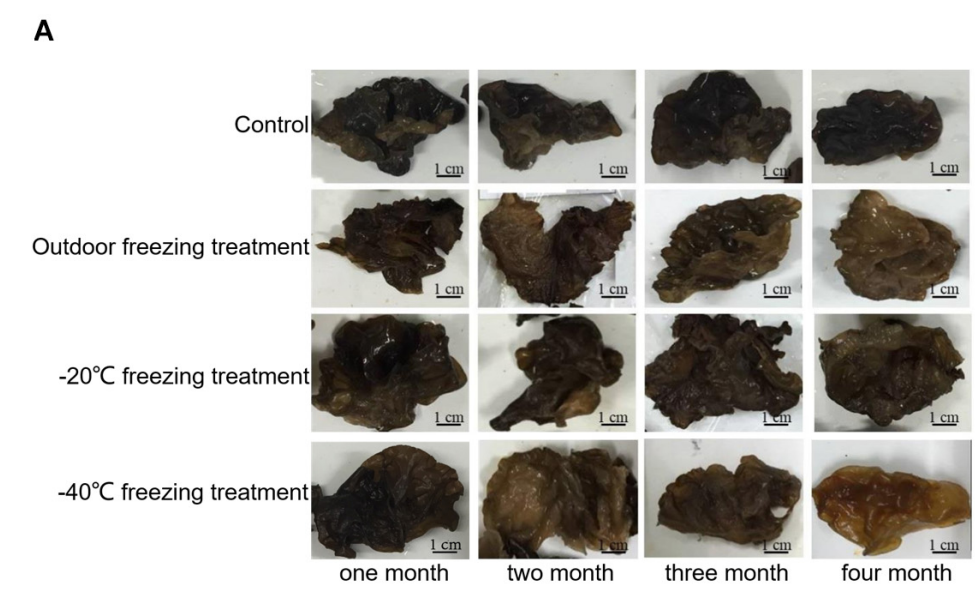

B

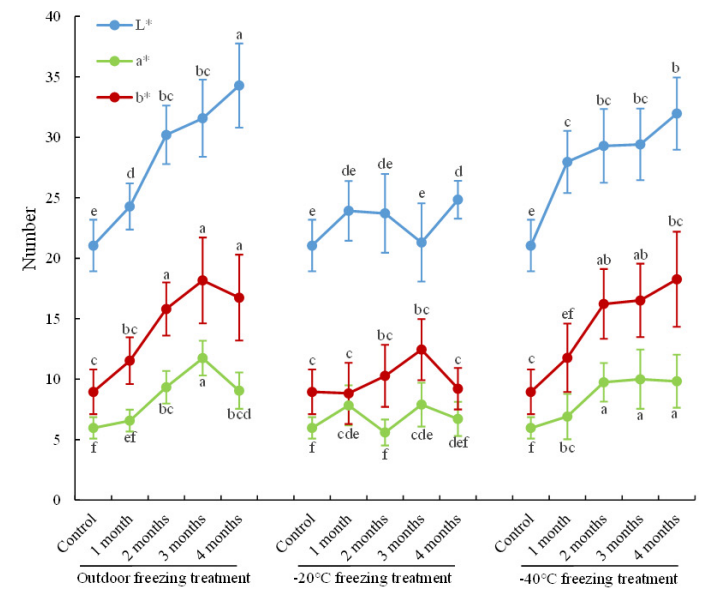

FIGURE 1 | Color changes of $A$. auricula-judae. (A) The color phenotype of fruiting bodies under outdoor, $-20^{\circ} \mathrm{C}$, and $-40^{\circ} \mathrm{C}$ freezing treatments for $1-4$ months. (B) The CIE L*-value (lightness), CIE a*-value (redness), and CIE b*-value (yellowness) of the fruiting bodies of $A$. auricula-judae were determined under outdoor, $-20^{\circ} \mathrm{C}$, and $-40^{\circ} \mathrm{C}$ freezing treatments. Different letters indicate statistically significant differences between the means $(p<0.05)$ for $L^{*}, a^{*}$, and $b^{*}$ calculated by one-way ANOVA.

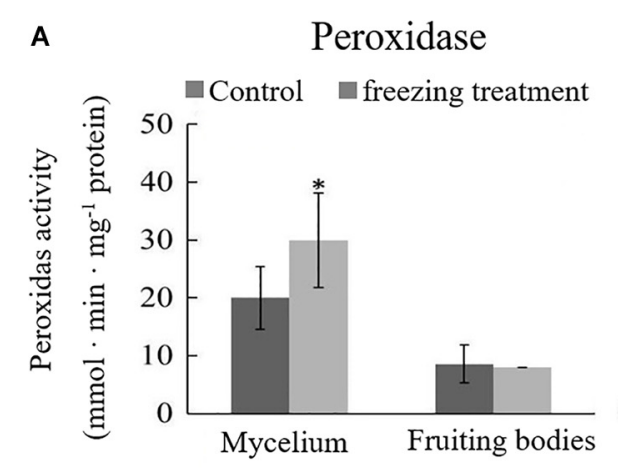

C

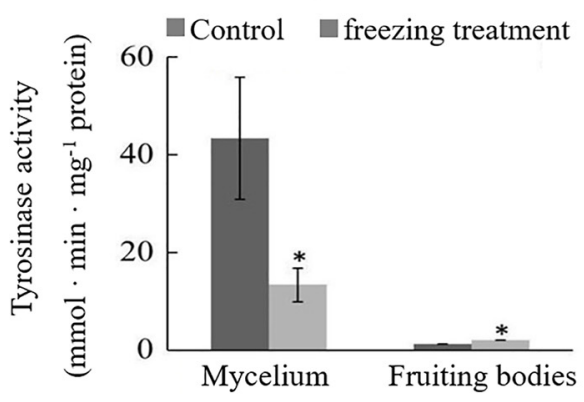

B

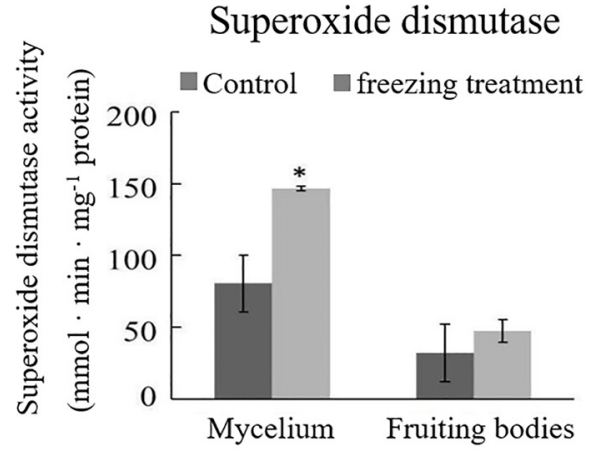

D

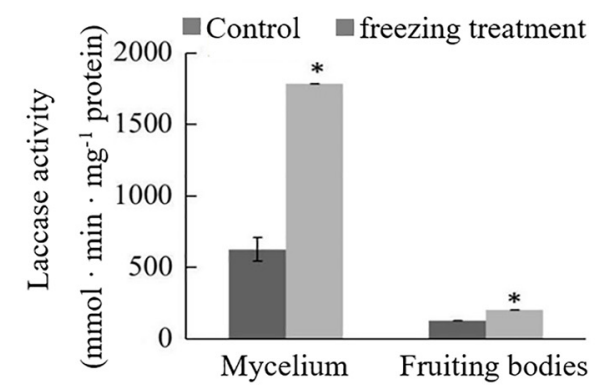

FIGURE 2 | Effects of outdoor freezing treatment on the enzyme activities of $A$. auricula-judae mycelium and fruiting bodies. The significant differences in the enzyme activities of (A) peroxidase, (B) superoxide dismutase, (C) tyrosinase, and (D) laccase between control and freezing-treated groups are indicated by an asterisk $(p<0.05)$ under outdoor freezing treatment. Values represent the means \pm SDs $(n \geq 3)$. Data were analyzed using Student's $t$-test.

of the activities of these two melanin synthases by freezing treatment may not result from the change of protein abundance. There were five proteins that exhibited changed expression in both the mycelium and fruiting bodies. The expression levels of ketol-acid reductoisomerase in the mycelium and fruiting bodies were similar, and the protein expression levels were upregulated after freezing treatment. The other three proteins, eukaryotic translation initiation factor 2 subunit alpha (EIF2S1), cyclophilin, and V-ATPase, were upregulated in the mycelium after freezing treatment but downregulated in the fruiting 

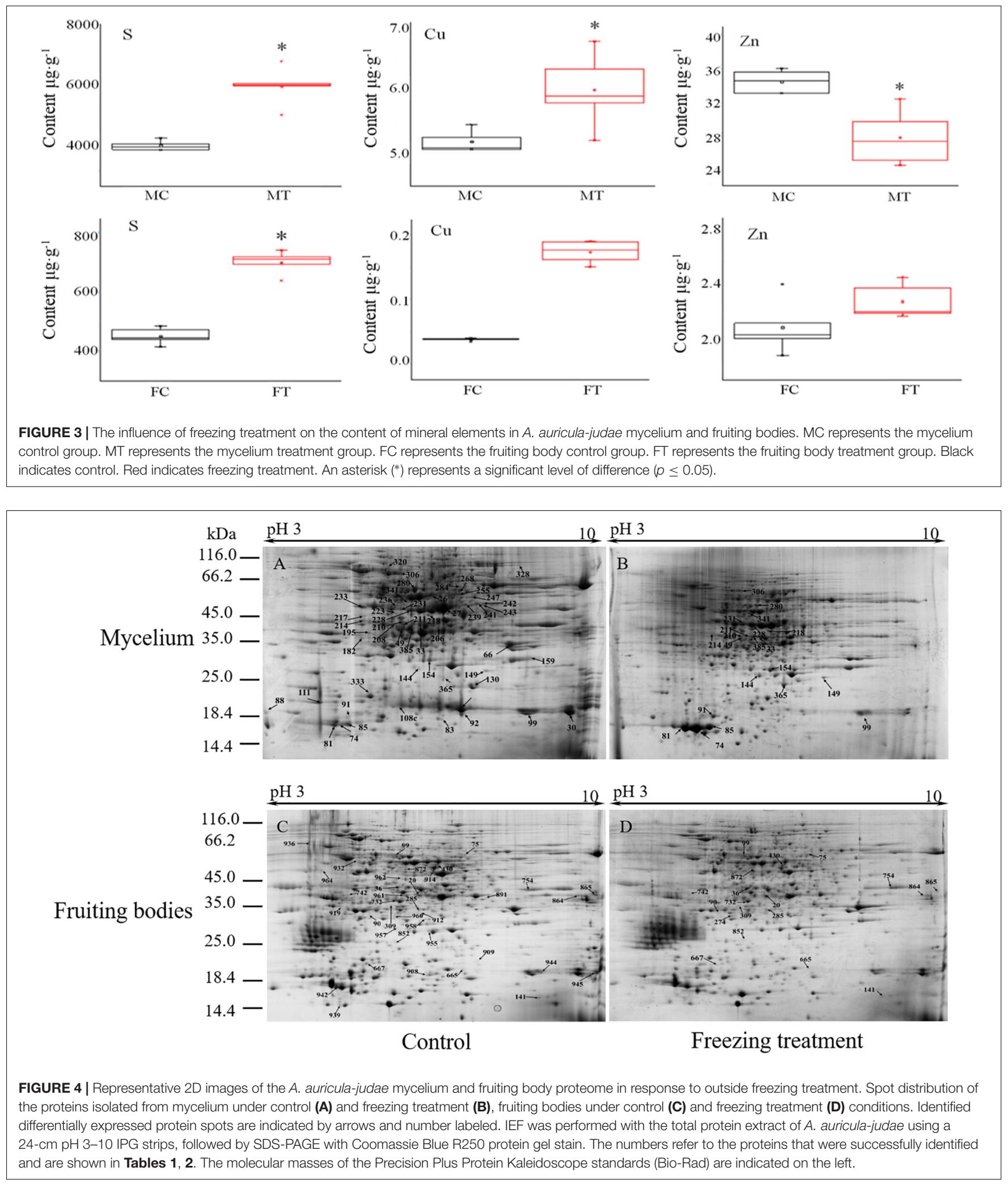

bodies. In contrast, the expression level of hypothetical protein AURDEDRAFT_158505 was downregulated in the mycelium but upregulated in the fruiting bodies after freezing treatment
(Figure 5B). This means that the physiological and mechanistic effects of freezing treatment on the mycelium and fruiting bodies of A. auricula-judae may be distinct. 
TABLE 1 | Protein identities and their relative changes under freezing treatment in A. auricula-judae mycelium.

\begin{tabular}{|c|c|c|c|c|c|c|c|c|}
\hline Spot No. ${ }^{a}$ & NCBI accession No. (GI) ${ }^{b}$ & Protein name & $\operatorname{Exp~pl/kDac}$ & Thero $\mathrm{pl} / \mathrm{kDa}^{\mathrm{d}}$ & Score ${ }^{e}$ & $\operatorname{sc}^{f}(\%)$ & $\mathrm{PN}^{\mathrm{g}}$ & Mycelium fold change \\
\hline \multicolumn{9}{|c|}{ Amino acid metabolism } \\
\hline 26 & gi| 393240892 & Iron-containing alcohol dehydrogenase 1 , partial & $6.60 / 44.38$ & $7.75 / 53.19$ & 107 & 2 & 1 & A \\
\hline 218 & gi| 393242110 & Ketol-acid reductoisomerase & $6.89 / 35.21$ & 8.83/43.89 & 58 & 2 & 1 & 3.33 \\
\hline 231 & gil 393246451 & 3-Isopropylmalate dehydrogenase & $6.18 / 36.54$ & $5.41 / 40.22$ & 202 & 8 & 2 & 6.71 \\
\hline 236 & gil 393246451 & 3-Isopropylmalate dehydrogenase & $5.82 / 40.90$ & $5.41 / 40.22$ & 205 & 8 & 2 & A \\
\hline 241 & gil 393245569 & Aspartate aminotransferase & $7.52 / 40.90$ & $8.23 / 46.37$ & 90 & 5 & 2 & A \\
\hline 242 & gil 393246788 & NAD(P)-binding protein & $7.71 / 40.43$ & $8.31 / 36.96$ & 221 & 8 & 2 & A \\
\hline 268 & gil 393237973 & Acetylglutamate kinase ARG6 & $7.23 / 45.38$ & $8.40 / 94.44$ & 168 & 3 & 2 & A \\
\hline 328 & gil 393245388 & Trehalose phosphorylase & $8.51 / 66.2$ & $6.39 / 82.73$ & 310 & 7 & 5 & $A$ \\
\hline \multicolumn{9}{|c|}{ Carbohydrate metabolism } \\
\hline 27 & gi| 393241500 & Citrate synthase & $6.70 / 40.43$ & $7.77 / 51.61$ & 100 & 6 & 2 & A \\
\hline 33 & gi| 393242616 & Transaldolase & $6.31 / 34.89$ & $6.62 / 35.77$ & 70 & 3 & 1 & 0.20 \\
\hline 210 & gi| 393236505 & Fructose-1,6-bisphosphatase & $6.32 / 34.68$ & $5.67 / 37.88$ & 103 & 4 & 1 & 0.39 \\
\hline 214 & gil 393246070 & Thiamin diphosphate-binding protein & $5.19 / 34.88$ & $4.98 / 36.16$ & 319 & 16 & 4 & 0.27 \\
\hline 284 & gil 393234096 & Hypothetical protein AURDEDRAFT_90114 & $7.21 / 50.87$ & $6.24 / 56.62$ & 146 & 8 & 3 & A \\
\hline \multicolumn{9}{|c|}{ Energy metabolism } \\
\hline 74 & gil 393245928 & V-type ATPase & $4.71 / 14.48$ & $5.75 / 68.67$ & 40 & 2 & 1 & 14.57 \\
\hline 81 & gil 393245928 & V-type ATPase & $4.55 / 14.49$ & $5.75 / 68.67$ & 43 & 2 & 1 & 6.13 \\
\hline 91 & gil 393245928 & V-type ATPase & $6.32 / 34.45$ & $5.75 / 68.67$ & 42 & 2 & 1 & 2.76 \\
\hline 385 & gi| 393246905 & Pyrophosphatase-domain-containing protein & $6.83 / 32.10$ & $5.70 / 32.97$ & 58 & 4 & 1 & 4.76 \\
\hline \multicolumn{9}{|c|}{ Genetic information processing } \\
\hline 159 & gi| 393247912 & Ribosomal protein $\mathrm{L} 13 \mathrm{e}$ & $8.63 / 25.38$ & $11.45 / 23.64$ & 154 & 16 & 3 & A \\
\hline 195 & gil 393229618 & Ubiquitin, partial & $5.38 / 32.34$ & $6.81 / 8.94$ & 285 & 36 & 3 & A \\
\hline 211 & gil 393246789 & Bet v1-like protein & $6.39 / 34.23$ & $5.30 / 34.44$ & 60 & 6 & 2 & 0.36 \\
\hline 217 & gi| 393234431 & Eukaryotic translation initiation factor 2 subunit alpha & $5.17 / 35.23$ & $5.00 / 35.87$ & 99 & 4 & 1 & A \\
\hline 247 & gil 393232408 & $26 \mathrm{~S}$ proteasome subunit $\mathrm{P} 45$ & $7.42 / 43.89$ & $6.00 / 41.63$ & 75 & 4 & 1 & A \\
\hline 280 & gi| 393234431 & Eukaryotic translation initiation factor 2 subunit alpha & $6.25 / 46.47$ & $5.00 / 35.87$ & 41 & 4 & 1 & $0-$ \\
\hline 306 & gil 393247433 & Hypothetical protein AURDEDRAFT_178815 & $6.32 / 63.88$ & $5.58 / 70.71$ & 73 & 1 & 1 & 0.33 \\
\hline 341 & gil 393242042 & Galactose mutarotase-like protein & $6.21 / 41.89$ & $5.64 / 46.03$ & 83 & 4 & 2 & 11.12 \\
\hline \multicolumn{9}{|c|}{ Metabolism of cofactors and vitamins } \\
\hline 144 & gil 393245268 & Hypothetical protein AURDEDRAFT_158505 & $6.351 / 24.37$ & $6.99 / 22.90$ & 73 & 5 & 1 & 4.79 \\
\hline \multicolumn{9}{|c|}{ Nucleotide metabolism } \\
\hline 206 & gi| 393226636 & NAD(P)-binding protein & $6.891 / 33.45$ & $6.37 / 36.60$ & 68 & 3 & 1 & A \\
\hline
\end{tabular}


TABLE 1| Continued

\begin{tabular}{|c|c|c|c|c|c|c|c|c|}
\hline Spot No. ${ }^{a}$ & NCBI accession No. (Gl) ${ }^{b}$ & Protein name & $\operatorname{Exp~pl/kDac}$ & Thero $\mathrm{pl} / \mathrm{kDa}^{\mathrm{d}}$ & Score ${ }^{e}$ & $\operatorname{sc}^{f}(\%)$ & $\mathrm{PN}^{\mathrm{g}}$ & Mycelium fold change \\
\hline \multicolumn{9}{|c|}{ Transport and catabolism } \\
\hline 149 & gil 393228574 & Manganese superoxide dismutase & $7.56 / 24.31$ & $6.65 / 22.44$ & 216 & 15 & 3 & $A$ \\
\hline 365 & gil 393228574 & Manganese superoxide dismutase & $6.71 / 24.89$ & $6.65 / 22.44$ & 208 & 15 & 3 & A \\
\hline \multicolumn{9}{|c|}{ Glycan biosynthesis and metabolism } \\
\hline 83 & gil 9586355 & Glycoside hydrolase family 38 protein & $6.87 / 13.56$ & $5.83 / 119.98$ & 83 & 0 & 1 & A \\
\hline \multicolumn{9}{|c|}{ Lipid metabolism } \\
\hline 49 & gi| 393246546 & Prolyl aminopeptidase serine peptidase & $6.42 / 32.87$ & $5.60 / 35.70$ & 70 & 4 & 1 & 0.55 \\
\hline 320 & gi| 393234249 & Hypothetical protein AURDEDRAFT_153044 & $5.61 / 66.54$ & $6.53 / 79.80$ & 86 & 3 & 2 & A \\
\hline \multicolumn{9}{|c|}{ Metabolism of other amino acids } \\
\hline 154 & gil 393240170 & Glutathione S-transferase & $6.56 / 24.88$ & $6.43 / 23.47$ & 78 & 4 & 1 & 2.26 \\
\hline \multicolumn{9}{|c|}{ Metabolism of terpenoids and polyketides } \\
\hline 182 & gi| 393247824 & Isopentenyl diphosphate isomerase & $9.211 / 31.87$ & $5.22 / 28.86$ & 86 & 10 & 2 & A \\
\hline 233 & gi| 393247674 & GTP binding protein & $5.21 / 20.68$ & $5.06 / 41.44$ & 420 & 16 & 5 & A \\
\hline \multicolumn{9}{|l|}{ Unknown } \\
\hline 85 & gil 393244469 & YjgF-like protein & $5.51 / 14.49$ & $5.61 / 14.18$ & 34 & 7 & 1 & 0.44 \\
\hline 88 & gil 393238524 & Hypothetical protein AURDEDRAFT_63592 & $3.00 / 15.45$ & $5.27 / 13.16$ & 36 & 1 & 2 & A \\
\hline 99 & gi| 393230623 & Cyclophilin & $8.52 / 15.45$ & $8.78 / 17.49$ & 334 & 27 & 3 & 2.76 \\
\hline 208 & gil 393235619 & Hypothetical protein AURDEDRAFT_126065 & $5.83 / 34.15$ & $10.97 / 45.84$ & 37 & 2 & 1 & A \\
\hline 223 & gil 393243746 & Protein prenyltransferase & $5.81 / 36.78$ & $5.58 / 39.04$ & 163 & 10 & 3 & A \\
\hline 228 & gi| 393243670 & Putative cyanide hydratase & $6.21 / 36.58$ & $5.96 / 40.75$ & 172 & 10 & 3 & 4.58 \\
\hline 239 & gil 393227903 & Carbohydrate-binding module family 12 protein & $7.31 / 40.88$ & $6.18 / 36.27$ & 64 & 8 & 3 & A \\
\hline 243 & gi| 393245114 & Hypothetical protein AURDEDRAFT_111257 & $7.71 / 40.51$ & $7.93 / 11.14$ & 43 & 15 & 1 & A \\
\hline 255 & gil 393241515 & Proliferation-associated protein 1 & $7.23 / 43.25$ & $7.61 / 42.43$ & 147 & 7 & 3 & $A$ \\
\hline
\end{tabular}

Two treatments including CK (control check) and OS (2 months outside freezing treatment) were performed; protein spots showing significant differences ( $n=3,1.5$-fold, $p \leq 0.05)$ were cut out and identified by $L C$-MS. ${ }^{a}$ Assigned spot number as indicated in Figures $4 A, B$. ${ }^{b}$ Database accession numbers according to NCBI database. ${ }^{c}$ Theoretical and dexperimental mass (kDa) and pl of identified proteins. Experimental values were calculated using ImageMaster 2D Platinum software. Theoretical values were retrieved from the protein database. 'EStatistical probability of true positive identification of the predicted protein calculated by MASCOT.

${ }^{f}$ Sequence coverage. ${ }^{~ N}$ Number of peptides sequenced. "Mean of relative protein abundance and standard error. "A" represents the protein spots deleted after treatment compared with the control group. 
TABLE 2 | Protein identities and their relative changes under freezing treatment in A. auricula-judae fruiting bodies.

\begin{tabular}{|c|c|c|c|c|c|c|c|c|}
\hline Spot no. ${ }^{a}$ & NCBI accession no. $(\mathrm{Gl})^{\mathrm{b}}$ & Protein name & $\operatorname{Exp~pl/kDac}$ & Thero $\mathrm{pl} / \mathrm{kDa}^{\mathrm{d}}$ & Score ${ }^{e}$ & $\operatorname{sc}^{f}(\%)$ & $\mathrm{PN}^{\mathrm{g}}$ & Fruit body fold change \\
\hline \multicolumn{9}{|c|}{ Genetic information processing } \\
\hline 36 & gil 393243821 & Serine/threonine-protein phosphatase PP1 & $5.81 / 37.231$ & $5.78 / 38.48$ & 107 & 11 & 3 & 5.88 \\
\hline 99 & gil 393234431 & Eukaryotic translation initiation factor 2 subunit alpha & $5.73 / 47.11$ & $5.00 / 35.87$ & 41 & 4 & 1 & 2.58 \\
\hline 667 & gil 393245529 & L30e-like protein & $5.28 / 21.33$ & $5.38 / 16.36$ & 175 & 21 & 3 & 0.43 \\
\hline 732 & gil 393245027 & Guanine nucleotide binding protein beta subunit & $5.67 / 35.112$ & $5.80 / 35.14$ & 281 & 11 & 3 & 0.38 \\
\hline 742 & gil 393241577 & Serine/threonine-specific protein phosphatase Sit4 & $4.79 / 18.321$ & $4.96 / 35.63$ & 186 & 13 & 3 & 0.33 \\
\hline 865 & gil 393232568 & $40 \mathrm{~S}$ ribosomal protein S3 & $8.94 / 34.47$ & $9.20 / 29.64$ & 431 & 23 & 6 & 0.42 \\
\hline 872 & gil 393235988 & Hypothetical protein AURDEDRAFT_167263 & $5.9 / 45.21$ & $5.96 / 43.11$ & 73 & 3 & 1 & 0.32 \\
\hline 909 & gil 393240875 & $60 S$ ribosomal protein L35 & $7.2 / 24.14$ & $10.79 / 14.80$ & 41 & 10 & 1 & A \\
\hline 945 & gil 393227063 & Ribosomal protein L14b/L23e & $9.47 / 20.11$ & $10.17 / 15.15$ & 137 & 14 & 2 & A \\
\hline \multicolumn{9}{|c|}{ Transport and catabolism } \\
\hline 90 & gil 393241397 & Ras-like protein & $5.34 / 33.32$ & $5.09 / 24.68$ & 182 & 12 & 2 & 2.11 \\
\hline \multicolumn{9}{|c|}{ Carbohydrate metabolism } \\
\hline 285 & gil 393240494 & Phosphomannomutase & $6.25 / 33.13$ & $5.73 / 29.56$ & 131 & 8 & 2 & 2.20 \\
\hline 430 & gil 393246246 & GroES-like protein & $6.41 / 46.33$ & $6.96 / 45.11$ & 173 & 13 & 4 & 3.21 \\
\hline 754 & gil 346995726 & Glyceraldehyde 3-phosphate dehydrogenase & $8.15 / 39.87$ & $8.18 / 36.53$ & 336 & 12 & 3 & 0.14 \\
\hline \multicolumn{9}{|c|}{ Amino acid metabolism } \\
\hline 309 & gil 18840885 & Hypothetical protein DICSQDRAFT_180523 & $5.74 / 34.89$ & $6.78 / 30.13$ & 70 & 5 & 1 & 2.93 \\
\hline 914 & gil 393246246 & GroES-like protein & $6.41 / 46.42$ & $5.97 / 42.92$ & 64 & 3 & 1 & A \\
\hline 962 & gil 393242110 & Ketol-acid reductoisomerase & $5.89 / 43.14$ & $8.83 / 43.89$ & 146 & 5 & 2 & A \\
\hline \multicolumn{9}{|c|}{ Energy metabolism } \\
\hline 942 & gil 393245928 & V-type ATPase & $4.74 / 18.01$ & $5.755 / 68.67$ & 41 & 2 & 1 & A \\
\hline \multicolumn{9}{|c|}{ Metabolism of cofactors and vitamins } \\
\hline 955 & gi| 393245268 & Hypothetical protein AURDEDRAFT_158505 & $6.38 / 27.09$ & $6.99 / 22.90$ & 52 & 5 & 1 & A \\
\hline 957 & gil 393245268 & Hypothetical protein AURDEDRAFT_158505 & $5.89 / 27.51$ & $6.99 / 22.90$ & 52 & 11 & 3 & A \\
\hline \multicolumn{9}{|c|}{ Nucleotide metabolism } \\
\hline 958 & gil 393230751 & Cleavage and polyadenylation-specific factor 5 & $6.26 / 36.89$ & $6.23 / 23.90$ & 38 & 7 & 1 & A \\
\hline \multicolumn{9}{|c|}{ Signal transduction } \\
\hline 961 & gil 393234194 & Casein kinase I homolog 1 & $5.81 / 36.73$ & $5.63 / 35.47$ & 64 & 2 & 1 & A \\
\hline \multicolumn{9}{|l|}{ Unknown } \\
\hline 75 & gil 393242075 & Peptidase C14 & $6.92 / 63.01$ & $5.58 / 34.27$ & 85 & 4 & 1 & 2.04 \\
\hline 141 & gi| 393243143 & Chaperonin Cpn10 & $8.29 / 16.43$ & $8.01 / 11.32$ & 51 & 9 & 1 & 6.04 \\
\hline 665 & gil 393230623 & Cyclophilin & $6.93 / 21.91$ & $8.78 / 17.49$ & 120 & 11 & 1 & 0.40 \\
\hline 852 & gil 393246485 & E set domain-containing protein & $5.76 / 26.34$ & $5.28 / 21.65$ & 78 & 8 & 1 & 0.47 \\
\hline 864 & gil 393243068 & Voltage-dependent ion-selective channel & $8.91 / 26.77$ & $9.05 / 31.92$ & 228 & 9 & 2 & 0.26 \\
\hline 919 & gil 393246271 & Hypothetical protein AURDEDRAFT_110532 & $4.92 / 34.89$ & $4.89 / 21.82$ & 142 & 9 & 1 & A \\
\hline 944 & gi| 393230623 & Nucleoside diphosphate kinase & $8.35 / 20.89$ & $7.85 / 16.69$ & 129 & 14 & 2 & A \\
\hline 960 & gil 393230539 & Hypothetical protein AURDEDRAFT_92020 & $5.87 / 32.22$ & $6.28 / 73.05$ & 120 & 5 & 2 & A \\
\hline
\end{tabular}

Two treatments including CK (control check) and OS (2 months outside freezing treatment) were performed; protein spots showing significant differences ( $n=3,1.5$-fold, $p \leq 0.05$ ) were cut out and identified by LC-MS. ${ }^{a}$ Assigned spot number as indicated in Figures $4 C, D$. ${ }^{b}$ Database accession numbers according to NCBI database. ${ }^{c}$ Theoretical and dexperimental mass (kDa) and pl of identified proteins. Experimental values were calculated using ImageMaster 2D Platinum software. Theoretical values were retrieved from the protein database. ${ }^{\circ}$ Statistical probability of true positive identification of the predicted protein calculated by MASCOT. ${ }^{f}$ Sequence coverage. ${ }^{g}$ Number of peptides sequenced. "Mean of relative protein abundance and standard error. "A" represents the protein spots deleted after treatment compared with the control group. 


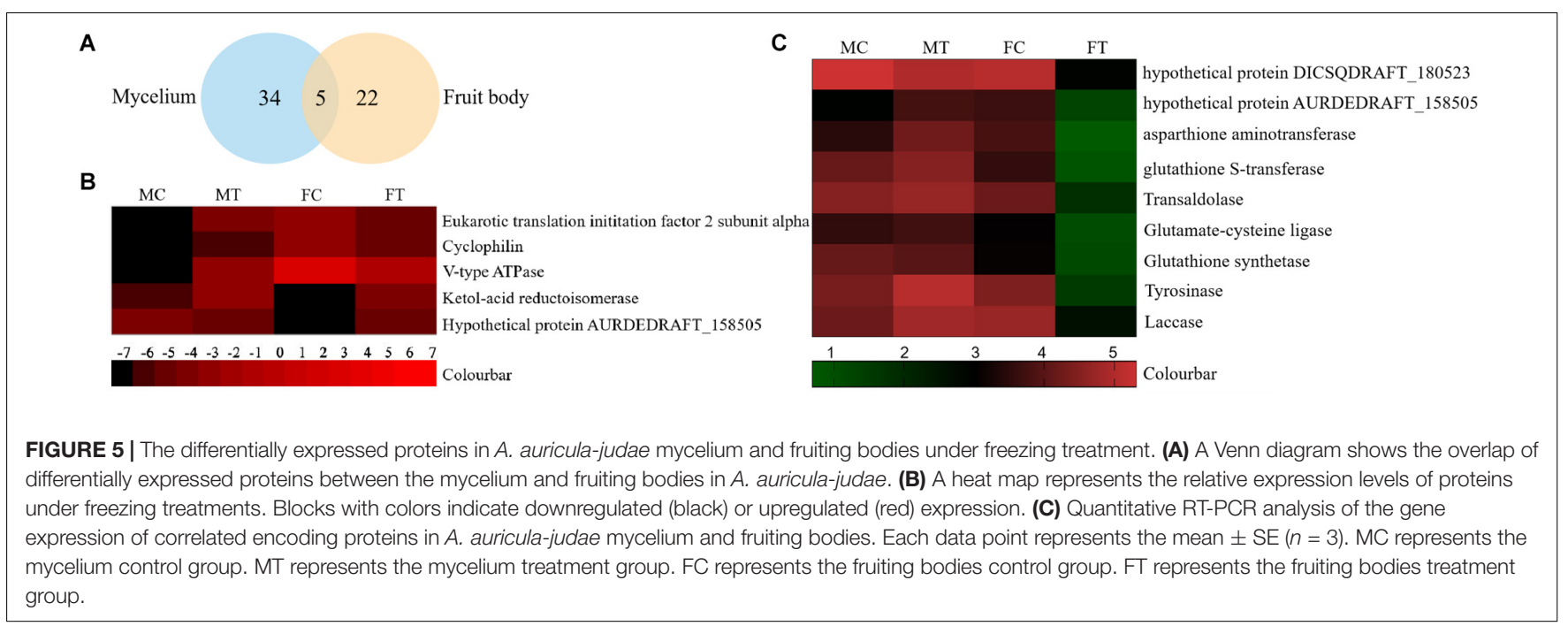

\section{Gene Expression}

As proteomics studies showed, the protein expression of tyrosinase and laccase was not affected by freezing treatment in both the mycelium and fruiting bodies. This means that the regulation of the activity of these two melanin synthases did not depend on the protein abundance. To check if the differentially expressed proteins are correlated with their gene expression at the transcription level, nine genes were selected to perform the qRT-PCR analysis (Figure 5C). The expression of four transcripts in the fruiting bodies was consistent with the abundances of the corresponding proteins, including hypothetical protein AURDEDRAFT_158505, aspartate aminotransferase, glutathione S-transferase, and transaldolase. The transcription of glutathione S-transferase in the mycelium was consistent with the abundance of the corresponding protein. This indicated that the accumulation of these proteins is due to the upregulated mRNA expression. However, the transcript expression for the hypothetical protein AURDEDRAFT_158505, aspartate aminotransferase, and glutathione S-transferase in the mycelium and hypothetical protein DICSQDRAFT_180523 in the fruiting bodies showed contrary results to their protein abundances. The expression of these four genes was downregulated in the fruiting bodies and upregulated in the mycelium, except for glutathione synthetase (Figure 5C), and the expression changes in these proteins could be caused by glycosylation, protein phosphorylation, protein degradation, and ubiquitination under freezing treatment.

\section{Functional Annotation of the A. auricula-judae Proteome}

The KEGG pathway analysis classified the functions of proteins into 12 groups involved in different metabolic pathways of the mycelium, mainly including genetic information processing (18\%), amino acid metabolism (15\%), and carbohydrate and energy metabolism (13\%). The proteins extracted from fruiting bodies were annotated into 10 groups, and the genetic information processing was significantly changed in the freezingtreated fruiting bodies (Figure 6A). We also analyzed the scatter plot of the significant KEGG enrichment function, and 20 and 15 pathways were enriched in the mycelium and fruiting bodies, respectively (Figure 6B). Among them, tyrosine metabolism, glycolysis/gluconeogenesis, ribosome, pantothenate and CoA biosynthesis, porphyrin and chlorophyll metabolism, cysteine and methionine metabolism, and oxidative phosphorylation showed co-enrichment in the mycelium and fruiting bodies. Glycolysis/gluconeogenesis, tyrosine metabolism, and arginine biosynthesis were mainly enriched in the mycelium. Ribosome, glycolysis/gluconeogenesis, and mRNA surveillance pathways were mainly enriched in the fruiting bodies. The key enzyme involved in the synthesis of all types of melanin from the initial precursor tyrosine is tyrosinase (Hearing, 2011), and tyrosine metabolism was mainly enriched in the mycelium. We infer that the melanin synthesis begins in the mycelium stage. This speculation was consistent with the enzyme activity results.

\section{UV-Visible/FTIR Spectra of A. auricula-judae Melanin Under Freezing Treatment}

We conducted FTIR and UV analyses of melanin in the fruiting bodies after freezing treatment (Supplementary Figure 3). In the FTIR spectrum detection, we found that the wide peak of $400 \mathrm{~cm}^{-1}$ was the $\mathrm{O}-\mathrm{H}$ stretching vibration of phenol. The absorption peak of $2950-850 \mathrm{~cm}^{-1}$ is the $\mathrm{C}-\mathrm{H}$ stretching vibration of the aliphatic group, and the absorption peak of $1450 \mathrm{~cm}^{-1}$ is the $\mathrm{C}-\mathrm{C}$ stretching vibration of the aliphatic group, indicating that there may be a small amount of protein in the two melanin species. The absorption peaks of $1600-1650 \mathrm{~cm}^{-1}$ were aryl skeleton $\mathrm{C}=\mathrm{C}$ and carboxyl stretching vibration, and the peaks of $1380-1400 \mathrm{~cm}^{-1}$ were phenolic hydroxyl bending vibration and $\mathrm{N}-\mathrm{H}$ stretching vibration in indole. In addition, the weak absorption peak within the range of 800$600 \mathrm{~cm}^{-1}$ indicates that aromatic rings are replaced, forming a conjugated system, and the content of aromatic hydrogen 
A

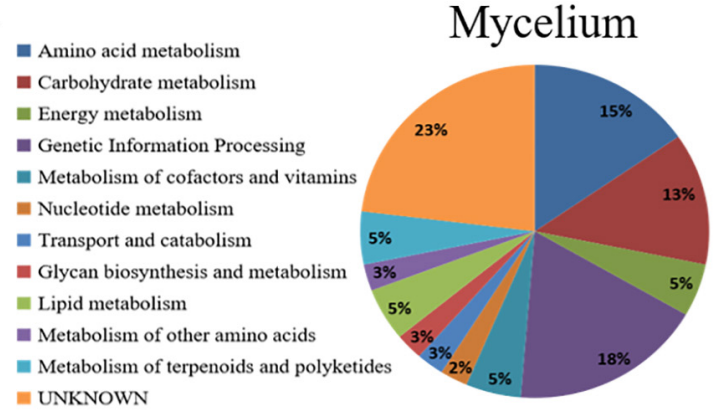

B

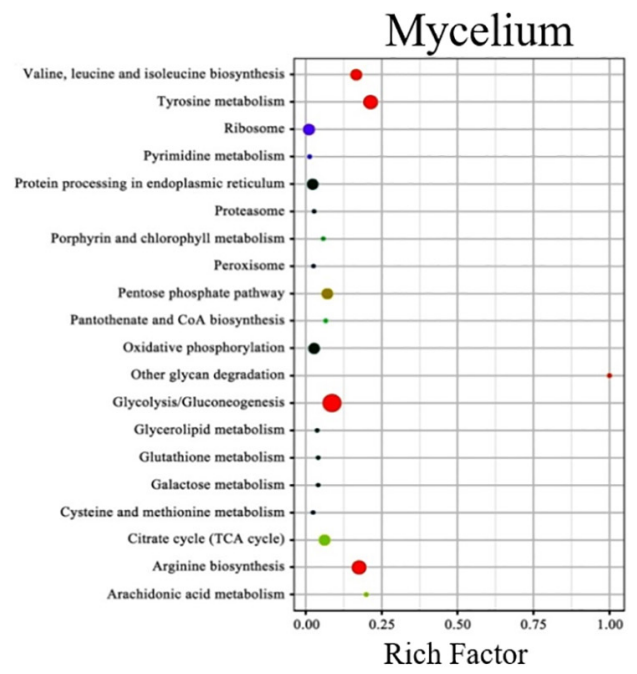

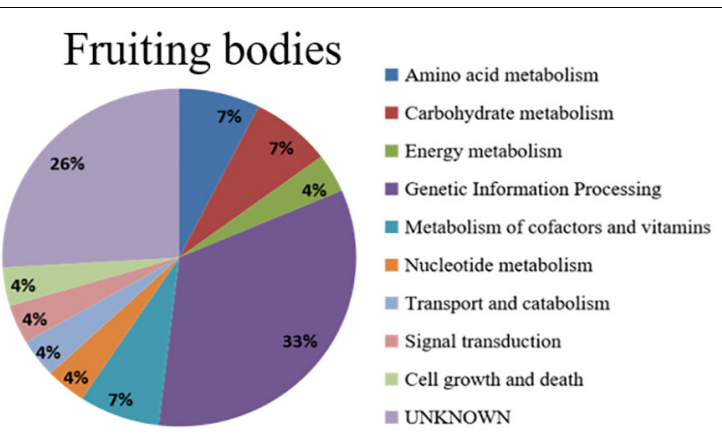

Fruiting bodies

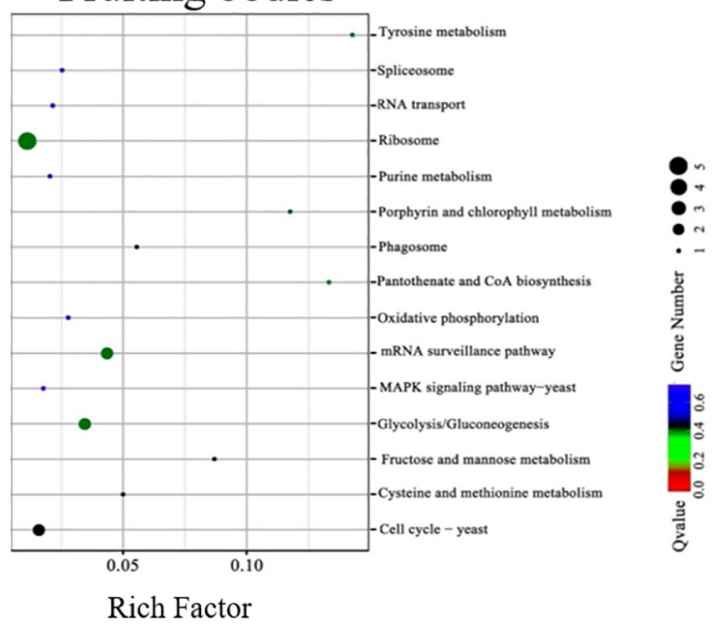

FIGURE 6 | The COG and KEGG pathway enrichment of differentially expressed proteins. (A) The distribution of the functional categories of proteins expressed in the mycelium and fruiting bodies under freezing treatment. The pie chart displays the proportion of identified proteins assigned to different functional categories according to the COG functional classification. (B) KEGG pathway enrichment of differently expressed proteins in the mycelium and fruiting bodies. The color of the dots represents the adjusted $p$-value, and the size of the dots represents the number of differently expressed proteins that were identified in the pathway.

is low. However, the absorption peak of melanin in control and freezing treatments is not significantly different, possibly because it contains a small amount of proteins to cover up the differences in structure (Supplementary Figure 3A). The UV absorption spectra of the A. auricula-judae melanin are similar (Supplementary Figure 3B), showing a stronger absorption at 200-300 $\mathrm{nm}$. In addition, the melanin has more absorption than the melanin under freezing treatment in the UV region, possibly because the former contains more eumelanin.

\section{EPR Analysis of $A$. auricula-judae Melanin Analysis}

Electron paramagnetic resonance spectra were recorded using the X-band Bruker Elexsys 500 spectrometer (Karlsruhe, Germany) with $100-\mathrm{kHz}$ field modulation and $9.849554-\mathrm{GHz}$ microwave frequency at $77 \mathrm{~K}$ and at room temperature. The calculated $g$ (2.004) indicates the presence of free radicals in the control and freezing treatment samples, which are the characteristic signals of all melanin and do not appear in any other biological tissues or non-melanin compounds that do not contain melanin (Supplementary Figure 4).

\section{DISCUSSION}

Freezing treatment is the most important step to cultivate A. auricula-judae, which is correlated with the growth rate, color formation, and biomass yield. Freezing treatment could improve the growth but negatively affect the color quality of fruiting bodies of $A$. auricula-judae. Until now, limited information has been available regarding the physiological and molecular mechanisms of how the freezing treatment impacts the growth and color of the mushroom. In our study, proteomic analysis was carried out, and the protein expression profiles of A. auriculajudae mycelium and fruiting bodies after freezing treatment showed that multiple biological processes, such as carbon metabolism, energy metabolism, biosynthesis of amino acids, protein processing and transport, and nucleotide metabolism, could be involved in the growth and color formation of A. auricula-judae.

From the observation of the color phenotype, the fruiting bodies obviously turn yellow after outdoor freezing treatment for 2 months (Figure 1A). In low-temperature environments, plants and fungi increase the activity of POD and SOD in the body, forming an active oxygen scavenging system to deal with the 


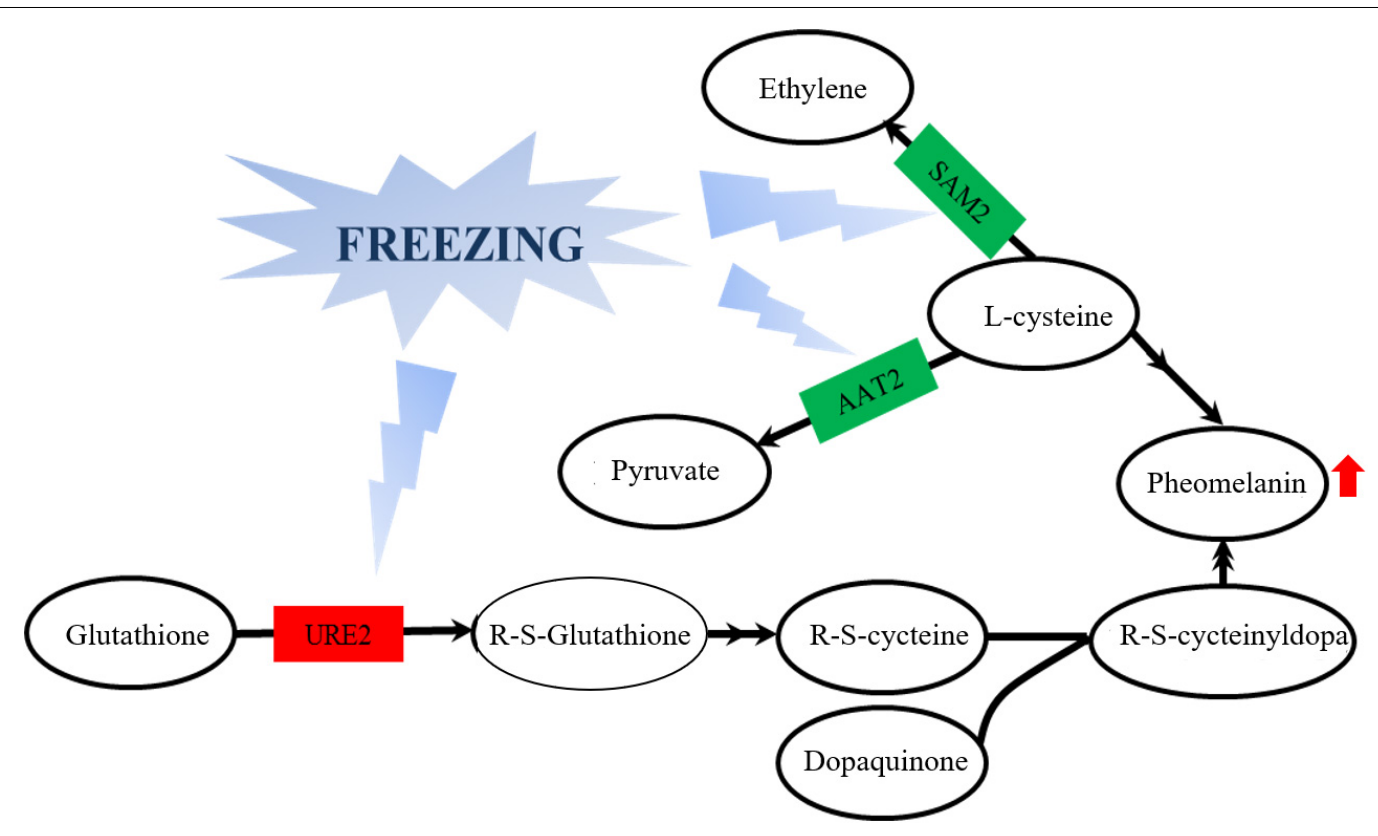

FIGURE 7 | Effects of glutathione S-transferase, aspartate aminotransferase, and methionine adenosyltransferase on melanin metabolism of the A. auricula-judae mycelium under freezing treatment. The double arrow means the direct action and the single arrow means the indirect action happened between two factors in the nodes. Red represents upregulation, while green represents downregulation. AAT2, aspartate aminotransferase; URE2, glutathione S-transferase; SAM2, methionine adenosyltransferase.

oxidative stress caused by low temperature (Zhang et al., 2013). The antioxidant enzyme involved in the regulation process of oxidative stress can oxidize the precursor, 2-S-cysteine DOPA quinone, and 5-S-cysteine DQ of pheomelanin, subsequently affecting the DOPA-melanin synthesis process (Galván and Alonsoalvarez, 2009). In the mycelium, the expression of manganese SOD (spot 149) was upregulated, which is consistent with the increase of the enzyme activity (Figure 2A). These results indicated that freezing treatment produces oxidative stress on the mycelium of A. auricula-judae. This may have some effects on the melanin synthetic process in the mycelium (Figure 2). The mixing ratio of melanin to eumelanin or pheomelanin during synthesis depends on the tyrosinase activity and substrate concentration of cysteine, which is involved in glutathione synthesis (Simon et al., 2009). Glutathione is implicated in the biogenesis of the pheomelanin (Benathan et al., 1999), and glutathione $S$-transferase (spot 154) is a key enzyme in the glutathione binding reaction that catalyzes the initial step of the reaction of glutathione binding (Chen et al., 2013), which may lead to the incremental accumulation of cysteine in the mycelium (Figure 7). When cysteine is present in the cell, DQ will immediately bind to cysteine to form cysteamine DOPA and then through multiple enzymatic reactions produce pheomelanin (Ito and Wakamatsu, 2003). As KEGG pathways show, methionine adenosyltransferase (SAM2) and aspartate aminotransferase (AAT2) are involved in cysteine metabolism and catalyze the reaction of aminoacrylate production, which is the precursor of L-cysteine. Our study found that the expression of SAM2 and AAT2 was downregulated after freezing treatment, and for support, the content of cysteine significantly decreased in the fruiting body (Supplementary Figure 5), which may influence the production of pheomelanin and the color quality of A. auricula-judae under freezing conditions (Figure 7). In addition, the increase of $S$ element content after freezing treatment is consistent with the description of Zou et al. (2013), which indirectly proves that the synthesis of melanin after freezing treatment tends to synthesize pheomelanin, somehow indicating that the accumulation of pheomelanin may be induced by freezing and then brings about the color change of fruiting bodies.

Our study showed that differentially expressed proteins (spots $210,214,26,242$, and 341) in the mycelium were involved in the glycolysis/gluconeogenesis process (Table 1), which is the main process contributing to the high-efficiency production of biomass. The galactose mutarotation enzyme (spot 341) presented an 11.12-fold increase with the freezing treatment. Galactose induces cellulase production in lactose metabolism (Seiboth et al., 2002), which indicates that the utilization rate of the cultivated substrate in the mycelium was enhanced after freezing treatment. Methionine adenosyltransferase (spot 914) was identified as the GroES-like protein SFA1, which is involved in the glycolysis/gluconeogenesis pathway, and the increased abundance of SFA1 indicated that the utilization rate of fruiting bodies to the cultivated substrate was enhanced after freezing treatment (Yu et al., 2015). Among the differentially expressed proteins in the fruiting bodies (Table 2), phosphomannomutase (spot 285) was involved in the metabolism of fructose and mannose simultaneously and at the same time also involved in the protein posttranslational modification, providing the glycosylation proteoglycan core, which is the main component 
of the cell wall of the edible fungus (Seifert, 2004). Therefore, the upregulated expression of phosphomannomutase suggested that the cell wall of the fruiting bodies may be strengthened after the freezing treatment, resulting in a larger form of the fruiting bodies. Ribosomal protein L23 (spot 945), as a negative regulator in cell apoptosis (Wu et al., 2012), exhibited reduced expression after freezing treatment, which indicated that most of the cells in the fruiting bodies are mature. The expression of serine/threonine protein phosphatase (spot 36) in the fruiting bodies is upregulated after freezing treatment, which is an indispensable regulatory factor for the G2-M phase of the cell cycle in winemaking yeast (Thakur and Sanyal, 2011). The increased expression of serine/threonine-protein phosphatase may improve the mitotic activity in the fruiting bodies and then promote the growth and maturation of fruiting bodies. Raslike protein (spot 90) is mainly located in the inner side of the cell membrane and plays an important role in the regulation of cell proliferation and cell metabolism (Yang, 2010). The greater expressed abundance of Ras-like protein indicated that the cell wall of fruiting bodies may be enlarged, leading to the larger morphology of fruiting bodies.

Branched-chain amino acids (BCAAs) are essential amino acids of the human body, and they are limited to plants and some microorganisms. They must be obtained through food and are valued for their nutritional applications (Shi and Yuan, 2003). BCAAs mainly include leucine, isoleucine, and valine. Ketol-acid reductoisomerases (spot 218) are a family of NADPH-dependent oxidoreductases, which are essential intermediates in the biosynthesis of BCAAs (Polaina, 1984). 3-Isopropylmalate dehydrogenase (spot 231) is a key enzyme for leucine biosynthesis, which is ultimately broken down into acetyl-CoA and acetoacetic acid and then enters the tricarboxylic acid cycle (Shmomura et al., 2006). Aspartic acid transaminase can convert phenylpyruvate (PPA) into L-phenylalanine in the presence of coenzyme pyridoxal phosphate (PLP) by using Laspartic acid as the amino donor and PPA as the substrate. L-Phenylalanine is a nutritional supplement and one of the essential amino acids (Wei et al., 2000). The expression levels of ketol-acid reductoisomerases, 3-isopropylmalate dehydrogenase, and aspartic acid transaminase were significantly increased in the mycelium after freezing treatment, which indicated that the nutritional value of $A$. auricula-judae fungus might be increased after freezing treatment.

Overall, the present study provides evidence that tyrosinase and laccase impact the synthesis of melanin and then affect the color quality of $A$. auricula-judae fruiting bodies. The complete

\section{REFERENCES}

Akpaja, E. O., Okhuoya, J. A., and Ehwerheferere, B. A. (2005). Ethnomycology and indigenous uses of mushrooms among the binispeaking people of Nigeria: A case study of aihuobabekun community near Benin City, Nigeria. Int. J. Med. Mushrooms 7, 373-374. doi: 10.1615/IntJMedMushrooms. v7i3.270

Benathan, M., Virador, V., Furumura, M., Kobayashi, N., Panizzon, R. G., and Hearing, V. J. (1999). Coregulation of melanin precursors and tyrosinase in human pigment cells: roles of cysteine and glutathione. Cell. Mole. Biol. protein expression profile uncovered the underlying mechanisms of the modulation of the color quality and fruit growth of A. auricula-judae under freezing conditions. The proteins involved in glycolysis/gluconeogenesis, tyrosine metabolism, and ribosome and arginine biosynthesis likely play a key role in the synthesis of melanin, and the expression changes of several metabolic enzymes in these pathways might influence the accumulation of pheomelanin. These proteins can be used as molecular markers in gene engineering to improve the melanin synthesis of $A$. auricula-judae in extreme environments. This study has provided a valuable basis for further understanding the molecular mechanism of the effect of the color of A. auriculajudae after freezing treatment and fruiting bodies formation, and it also gives theoretical evidence for the quality control and industrial application of A. auricula-judae.

\section{DATA AVAILABILITY STATEMENT}

The datasets presented in this study can be found in online repositories. The names of the repository/repositories and accession number(s) can be found in the article/ Supplementary Material.

\section{AUTHOR CONTRIBUTIONS}

QP, XY, and ZL conceived and designed the research. QP, XY, $\mathrm{ZL}$, JL, and $\mathrm{TZ}$ conducted the experiments. ZL contributed the new reagents or analytical tools. ZL, JL, and TZ analyzed the data. JL wrote the manuscript. All the authors read and approved the manuscript.

\section{FUNDING}

This research was financially supported by a grant from the Special Fund for Forest Scientific Research in the Public Welfare (Grant No. 201404703-7).

\section{SUPPLEMENTARY MATERIAL}

The Supplementary Material for this article can be found online at: https://www.frontiersin.org/articles/10.3389/fmicb. 2020.610173/full\#supplementary-material

45, 981-990. doi: 10.1002/(SICI)1097-0169(199911)44:3<225:AID-CM7>3.0. $\mathrm{CO} ; 2-\#$

Butler, M. J., and Day, A. W. (1998). Fungal melanins: a review. Can J. Microbiol. 44, 1115-1136. doi: 10.1139/cjm-44-12-1115

Chen, Q. X., and Song, K. K. (2006). Tyrosinase :Recent Prospects. J. Xiamen Univ. 45, 731-737. doi: 10.3321/j.issn:0438-0479.2006.05.033

Chen, Y. Z., Pang, Q. Y., Dai, S. J., Wang, Y., Chen, S. X., and Yan, X. F. (2011). Proteomic identification of differentially expressed proteins in Arabidopsis in response to methyl jasmonate. J. Plant Physiol. 168, 995-1008. doi: 10.1016/j. jplph.2011.01.018 
Chen, X. H., Wang, Z. Y., Li, X. P., Zhu, Y. M., Liu, L., Chen, W., et al. (2013). Research progress on glutathione S-transferases. J. Northeast Agric. Univ. 44, 149-153. doi: 10.13560/j.cnki.biotech.bull.1985.2016. 09.002

Dai, X. D., Zhang, J. C., Zhang, P. Q., Han, Z. H., Kong, X. H., Ma, Q. F., et al. (2014). A New Auricularia auricula Cultivar 'Heiwei 15'. Acta Horti. Sin. 46, 2829-2830. doi: 10.16420/j.issn.0513-353x.2019-0852

Geib, E., Gressler, M., Viediernikova, I., Hillmann, F., Jacobsen, I. D., Nietzsche, S., et al. (2016). A Noncanonical melanin biosynthesis pathway protects Aspergillus terreus conidia from environmental stress. Cell Chem. Biol. 23, 587-597. doi: 10.1016/j.chembiol.2016.03.014

Gao, Y. H. (2012). Cultivation experiment of Auricularia auricular. Edibie fungi China. 31, 64-68. doi: 10.13629/j.cnki.53-1054.2012.03.023

Galván, I., and Alonsoalvarez, C. (2009). The expression of melanin-based plumage is separately modulated by exogenous oxidative stress and a melanocortin. Proc. R. Soc. B. 276, 3089-3097. doi: 10.1098/rspb.2009.0774

Hearing, V. J. (2011). Determination of melanin synthetic pathways. J. Investig. Dermatol. 131, E8-E11. doi: 10.1038/skinbio.2011.4

Ito, S., and Wakamatsu, K. (2003). Quantitative analysis of eumelanin and pheomelanin in humans, mice, and other animals: a comparative review. Pigm. Cell Res. 16, 523-531. doi: 10.1034/j.1600-0749.2003 00072.x

Jarrar, M., Shafey, A. E., Essa, R., Damji, R., Rauf, A., and Hindi, I. (2017). Melanin relieves oxidative stress in adipocytes culture in vitro. Pharm. Biol. Eval. 4, 212-215. doi: 10.26510/2394-0859.pbe.2017.33

Kanehisa, M., Araki, M., Goto, S., Masahiro, H., Mika, H., Masumi, I., et al. (2008). KEGG for linking genomes to life and the environment. Nucleic Acids Res. 36, 480-484. doi: 10.1093/nar/gkm882

Li, B. (2011). Study on bacterial quorum sensing inhibition and antioxidant activity of melanin from Auricularia auricula. Nanjing Agricul. Univ. 2011: 2359948. doi: 10.7666/d.Y2359948

Li, Z. W., Han, D. M., Wang, M. C., Zhang, Y. X., Wang, Y., Yan, X. F., et al. (2018). Optimization of the Sample Preparation Procedure for the Determination of Trace Elements in Auricularia auricula by Inductively Coupled Plasma Optical Emission Spectrometry. Anal. Lett. 51, 1763-1773. doi: 10.1080/00032719.2017. 1385619

Li, J. Y., Chi, W., Liu, B., and Xu, Y. Q. (2019). Comparative Analysis of economic development status and production benefits of Auricularia auricula industry in China. Dible fungi 41, 6-8. doi: CNKI:SUN:SIYJ.0.2019-06-002

Liu, Y. F., and Hu, N. N. (2018). Research and development strategy of Auricularia auricula in heilongjiang province. Technol. Manag. 25, 1-3. doi: CNKI:SUN: TJYY.0.2018-01-001

Livak, K. J., and Schmittgen, T. D. (2001). Analysis of relative gene expression data using realtime quantitative PCR and the $2^{-\Delta \Delta \mathrm{Ct}}$ Method. Methods 25, 402-408. doi: 10.1006/meth.2001.1262

Lv, S. (2008). Bagged cultivation technology of northern Auricularia auricula. Edible Fungi China. 27, 59-60. doi: 10.13629/j.cnki.53-1054.2008.05.018

Luo, Y. C., Chen, G., Li, B., Ji, B. P., Yi, G., and Tian, F. (2009). Evaluation of antioxidative and hypolipidemic properties of a novel functional diet formulation of Auricularia auricula and Hawthorn. Food Sci. 10, 0-221. doi: 10.1016/j.ifset.2008.06.004

Nguyen, L., Chen, J., Hu, Y. L., Wang, D., Fan, Y. P., Wang, J. M., et al. (2012). In vitro antiviral activity of sulfated Auricularia auricula polysaccharides. Carbohydr Polym. 90, 1254-1258. doi: 10.1016/j.carbpol.2012.06.060

Polaina, J. (1984). Cloning of the ILV2, ILV3 and ILV5 genes of Saccharomyces cerevisiae. Carlsberg Res Commun. 49, 577-584. doi: 10.1007/BF0290 8686

Prota, G. (1980). Recent advances in the chemistry of melanogenesis in mammals. J. Investig. Dermatol. 75, 122-127. doi: 10.1111/1523-1747.ep12521344

Shmomura, Y., Honda, T., Shiraki, M., Murakami, T., Sato, J., Kobayashi, H., et al. (2006). Branched chain amino acid catabolism in exercise and liver disease1-3. J. Nutrit. 136, 250-253. doi: 10.1128/AEM.68.8.3848-3854.2002

Shi, R. F., and Yuan, H. P. (2003). Branched chain amino acids metabolism and exercise. J. Shanghai Physical Educ. Inst. 27, 65-67. doi: 10.16099/j.cnki.jsus. 2003.05.027

Seiboth, B., Karaffa, L., Sándor, E., and Kubicek, C. P. (2002). The Hypocrea jecorina gal10, (uridine $5^{\prime}$-diphosphate-glucose 4 -epimerase-encoding) gene differs from yeast homologues in structure, genomic organization and expression. Gene 295, 143-149. doi: 10.1016/S0378-1119(02)00834-X

Simon, J. D., Peles, D., Wakamatsu, K., and Ito, S. (2009). Current challenges in understanding melanogenesis: Bridging chemistry, biological control, morphology, and function. Pig Cell Melanoma Res. 22, 563-579. doi: 10.1111/j. 1755-148X.2009 00610.x

Sapmak, A., Boyce, K. J., Andrianopoulos, A., and Nongnuch, V. (2015). The pbrB gene encodes a laccase required for DHN-melanin synthesis in conidia of Talaromyces (Penicillium) marneffei. PLoS One. 10:e0122728. doi: 10.1371/ journal.pone.0122728

Seifert, G. J. (2004). Nucleotide sugar interconversions and cell wall biosynthesis: how to bring the inside to the outside. Curr. Opin. Plant Biol. 7, 277-284. doi: 10.1016/j.pbi.2004.03.004

Takeshi, K., Saeed, M., Lori, S. A. B., Masatoshi, M., Akihiko, I., Hirofumi, T., et al. (2016). Image analysis for a microfluidic paper-based analytical device using the CIE L*a*b* color system. Analyst 141, 6507-6509. doi: 10.1039/c6an01409g

Thakur, J., and Sanyal, K. (2011). The essentiality of the fungus-specific Dam1 complex is correlated with a one-kinetochore-one-microtubule interaction present throughout the cell cycle, independent of the nature of a centromere. Eukaryotic Cell 10, 1295-1305. doi: 10.1128/EC.05093-11

Wang, M., Gu, B., Huang, J., Jiang, S., Chen, Y., Yin, Y., et al. (2013). Transcriptome and proteome exploration to provide a resource for the study of Agrocybe aegerita. PLoS One. 8:e56686. doi: 10.1371/journal.pone.0056686

Wu, L. Y., Li, X., Xu, F., Chang, C. K., He, Q., Zhang, Z., et al. (2012). Overexpression of RPL23 in myelodysplastic syndromes is associated with apoptosis resistance of $\mathrm{CD} 34^{+}$cells and predicts poor prognosis and distinct response to CHG chemotherapy or decitabine. Ann. Hematol. 91, 1547-1554. doi: 10.1007/ s00277-012-1486-2

Wei, G. W., Wei, P., Zhou, H., and Ouyang, P. K. (2000). Studies on aspartate aminoteransferase and its characteristics. J. Nanjing Univ. Technol. 22, 19-22. doi: 10.3969/j.issn.1671-7627.2000.03.005

Yang, Q. Q. (2010). Era protein (E. coli ras-like protein)-Apossible new molecular switch participating in the eukaryotic and prokaryotic cells signal control. J. Beijing Inst. Educ. 5, 1-6. doi: 10.3969/j.issn.1673-6923.2010.02.001

Yao, Z. Y., Zhao, Z., Shi, Q. H., Li, K. Y., Zhu, H. L., Ma, X. H., et al. (2007). Isolation of melanin from testae of Prunus ameniaca Linn. J. Northwest A F Univ. 35, 120-126. doi: 10.3321/j.issn:1671-9387.2007.05.026

Yu, Z. Q., Yu, S. J., and Li, K. T. (2015). Research progresses on bioconversion of spent mushroom substrate lignocellulose forfuel ethanol production. Food Ferment Ind. 41, 235-239. doi: 10.13995/j.cnki.11-1802/ts.201505042

Zielinska, M., and Michalska, A. (2016). Microwave-Assisted Drying of Blueberry (Vaccinium corymbosum L.) Fruits: Drying Kinetics, polyphenols, anthocyanins, antioxidant capacity, colour and texture. Food Chem. 212, 671680. doi: 10.1016/j.foodchem.2016.06.003

Zou, Y., Yi, D. M., Jiang, J., Du, X. W., Liu, C. H., and Gu, Z. X. (2013). Composition Analysis and Antioxidant Activity of Auricularia auricula Melanin. Food Sci. Technol. 34, 138-141. doi: 10.7506/spkx1002-6630-201323029

Zhang, G. L., Bai, Y. J., Zhang, L., Xie, X. Y., and Feng, Z. S. (2013). Effect of low temperature treatment on laccase and tyrosinase and isoenzyme in Pleurotus ferulae. Food Sci. Technol. 38, 15-19. doi: 10.13684/j.cnki.spkj.2013. 07.007

Zhang, D. W., Zhao, L., Liu, T. J., Wu, T. X., and Yang, H. L. (2007). Progress on Biological Activities and Their Polysaccharides from Auricularia auricula. Food and Drug 9, 68-70. doi: 10.13386/jissn1002-0306.2015.16.071

Conflict of Interest: The authors declare that the research was conducted in the absence of any commercial or financial relationships that could be construed as a potential conflict of interest.

Copyright (c) $2021 \mathrm{Li}, \mathrm{Li}$, Zhao, Yan and Pang. This is an open-access article distributed under the terms of the Creative Commons Attribution License (CC BY). The use, distribution or reproduction in other forums is permitted, provided the original author(s) and the copyright owner(s) are credited and that the original publication in this journal is cited, in accordance with accepted academic practice. No use, distribution or reproduction is permitted which does not comply with these terms. 